\title{
Effectiveness of Primary Care-Based Vestibular Rehabilitation for Chronic Dizziness
}

Lucy Yardley, PhD; Margaret Donovan-Hall, MSc; Helen E. Smith, BSMS, DM; Bronagh M. Walsh, RN, PhD; Mark Mullee, MSc, CStat; and Adolfo M. Bronstein, FRCP, PhD

Background: Dizziness is a very common symptom and is usually managed in primary care. Vestibular rehabilitation for dizziness is a simple treatment that may be suitable for primary care delivery, but its effectiveness has not yet been determined.

Objective: To evaluate the effectiveness of nurse-delivered vestibular rehabilitation in primary care for patients with chronic dizziness.

Design: Single-blind randomized, controlled trial.

Setting: 20 general practices in southern England.

Patients: 170 adult patients with chronic dizziness who were randomly assigned to vestibular rehabilitation $(n=83)$ or usual medical care $(n=87)$.

Intervention: Each patient received one 30- to 40-minute appointment with a primary care nurse. The nurse taught the patient exercises to be carried out daily at home, with the support of a treatment booklet.

Measurements: Primary outcome measures were baseline, 3-month, and 6-month assessment of self-reported spontaneous and provoked symptoms of dizziness, dizziness-related quality of life, and objective measurement of postural stability with eyes open and eyes closed.

Results: At 3 months, improvement on all primary outcome measures in the vestibular rehabilitation group was significantly greater than in the usual medical care group; this improvement was maintained at 6 months. Of 83 treated patients, $56(67 \%)$ reported clinically significant improvement compared with 33 of $87(38 \%)$ usual care patients (relative risk, $1.78[95 \% \mathrm{Cl}, 1.31$ to 2.42]).

Limitations: Psychological elements of the therapy may have contributed to outcomes, and the treatment may be effective only for well-motivated patients.

Conclusions: Vestibular rehabilitation delivered by nurses in general practice improves symptoms, postural stability, and dizziness-related handicap in patients with chronic dizziness.

Ann Intern Med. 2004;141:598-605.

www.annals.org

For author affiliations, see end of text.

See editorial comment on pp 641-643.
D izziness is a very common symptom, with a prevalence as high as $25 \%$ in the general population $(1,2)$. One in 10 working-age adults report some degree of handicap due to dizziness (2); $2 \%$ experience chronic, frequent, substantially handicapping episodes (3). More than 1 in 5 people older than 60 years of age have current dizziness that has led to substantial disability, medical consultation, or medication use (4). Dizziness is also associated with falls, fear of falling, and loss of independence in older people $(5,6)$.

The most common cause of dizziness presenting in primary care is peripheral vestibular disorder. Psychiatric factors, which often accompany medical disorders, are also common causes. Serious cardiovascular or neurologic disease is rare $(1,7-11)$. A multifactorial syndrome is common in older people (12). Because of the numerous causes, patients may present in various specialties, but most are managed in primary care (8). Treatment typically consists of reassurance and antivertiginous and antiemetic drugs to relieve symptoms $(8,13-15)$. However, several reviews of the management of dizziness have concluded that no medication in current use has well-established curative or prophylactic value or is suitable for long-term palliative use. These reviews have called for evaluation of an exercisebased form of treatment known as vestibular rehabilitation (14-16).

The central element of vestibular rehabilitation is a program of graded exercises that consist of eye, head, and body movements designed to stimulate the vestibular system. This stimulation promotes central compensation, which is neurologic adaptation to the altered input from the damaged labyrinth $(13,17,18)$. These exercises also help patients to overcome fear and avoidance of activities that elicit disorientation and to regain skill and confidence in balance (19). Studies in secondary care (for example, otolaryngology, neurootology, or balance centers) have provided some evidence that vestibular rehabilitation may be an effective treatment for dizziness resulting from various conditions, including peripheral vestibular disorder, benign paroxysmal positional vertigo, anxiety, multifactorial dizziness in the elderly, and head injury (20-26). However, to date, no randomized, controlled trials of vestibular rehabilitation that conform to Consolidated Standards of Reporting Trials (CONSORT) criteria (27) have been reported; therefore, the efficacy and effectiveness of vestibular rehabilitation remain difficult to estimate. For example, some studies do not use intention-to-treat analysis $(20,22-26)$, some have very few participants in trials $(21,22)$, and some use unpublished subjective outcome measures rather than measures with known reliability and validity $(21,25,26)$.

Currently, vestibular rehabilitation is rarely made available to the many patients who are managed at the primary care level. It is a simple therapy with no require- 
ment for equipment; therefore, if effective, it would be highly suitable for more widespread provision in primary care. An earlier nonblinded randomized, controlled trial (28) has provided a preliminary positive evaluation of the efficacy of vestibular rehabilitation in a primary care sample that involved patients with various causes of the disorder. After 2 home visits from a research nurse with specialist training in vestibular rehabilitation, the treatment group demonstrated a decrease in symptom severity, reduced handicap, and better postural control (28). In the present study, we assessed the effectiveness of a single session of vestibular rehabilitation delivered by primary care nurses.

\section{Methods \\ Design}

We used a single-blind randomized, controlled design to compare vestibular rehabilitation with usual medical care. Participants were assessed at baseline and then randomly assigned to the intervention group. At 3 months, a research assistant who was blinded to treatment status reassessed each participant. In a single crossover design (29), during the next 3 months, the usual medical care group received vestibular rehabilitation, and both groups were reassessed by the blinded research assistant at 6 months. The South and West Local Research Ethics Committee and the South East Local Research Ethics Committee ap-

\section{Context}

Chronic dizziness is a common and difficult to manage symptom among primary care patients. Vestibular rehabilitation exercises improve symptoms in some patients, but primary care settings infrequently use this treatment.

\section{Contribution}

The authors randomly assigned patients to a 30- to 40minute session during which a nurse in a primary care setting taught them vestibular exercises or to a control group. Patients assigned to the nurse intervention had significantly greater improvement in dizziness symptoms than patients in the control group.

\section{Implications}

Nurse-delivered vestibular rehabilitation is a feasible and effective treatment option for primary care patients with chronic dizziness.

\section{-The Editors}

proved the study, and all participants gave signed informed consent.

\section{Participants}

We recruited participants in 2001 and 2002 from 20 general practices within a 30 -mile radius of Southampton,

Figure 1. Vertigo Symptom Scale (short form).

\section{Vertigo Symptom Scale (short form)}

We would like to know what dizziness-related symptoms you have had just recently. Please circle the appropriate number to indicate about how many times you have experienced each of the symptoms listed below during the past month. The range of responses is:

$\begin{array}{ccccc}0 & 1 & 2 & 3 & 4 \\ \text { Never } & \text { A few times } & \text { Several times } & \begin{array}{c}\text { Quite often } \\ \text { (every week) }\end{array} & \begin{array}{c}\text { Very often } \\ \text { (most days) }\end{array}\end{array}$

How often in the past month have you had the following symptoms:

1. A feeling that either you, or things around you, are spinning or moving, lasting less than $\mathbf{2 0}$ minutes

2. Hot or cold spells

3. Nausea (feeling sick), vomiting

4. A feeling that either you, or things around you, are spinning or moving, lasting more than 20 minutes

5. Heart pounding or fluttering

6. A feeling of being dizzy, disoriented or "swimmy," lasting all day

7. Headache, or feeling of pressure in the head

8. Unable to stand or walk properly without support, veering or staggering to one side

9. Difficulty breathing, short of breath

10. Feeling unsteady, about to lose balance, lasting more than $\mathbf{2 0}$ minutes

11. Excessive sweating

12. Feeling faint, about to black out

13. Feeling unsteady, about to lose balance, lasting less than $\mathbf{2 0}$ minutes

14. Pains in the heart or chest region

15. A feeling of being dizzy, disoriented or "swimmy," lasting less than 20 minutes

更

\begin{tabular}{|c|c|c|c|c|}
\hline 0 & 1 & 2 & 3 & 4 \\
\hline 0 & 1 & 2 & 3 & 4 \\
\hline 0 & 1 & 2 & 3 & 4 \\
\hline 0 & 1 & 2 & 3 & 4 \\
\hline 0 & 1 & 2 & 3 & 4 \\
\hline 0 & 1 & 2 & 3 & 4 \\
\hline 0 & 1 & 2 & 3 & 4 \\
\hline 0 & 1 & 2 & 3 & 4 \\
\hline 0 & 1 & 2 & 3 & 4 \\
\hline 0 & 1 & 2 & 3 & 4 \\
\hline 0 & 1 & 2 & 3 & 4 \\
\hline 0 & 1 & 2 & 3 & 4 \\
\hline 0 & 1 & 2 & 3 & 4 \\
\hline 0 & 1 & 2 & 3 & 4 \\
\hline 0 & 1 & 2 & 3 & 4 \\
\hline
\end{tabular}


Figure 2. Participants at each stage of the trial.

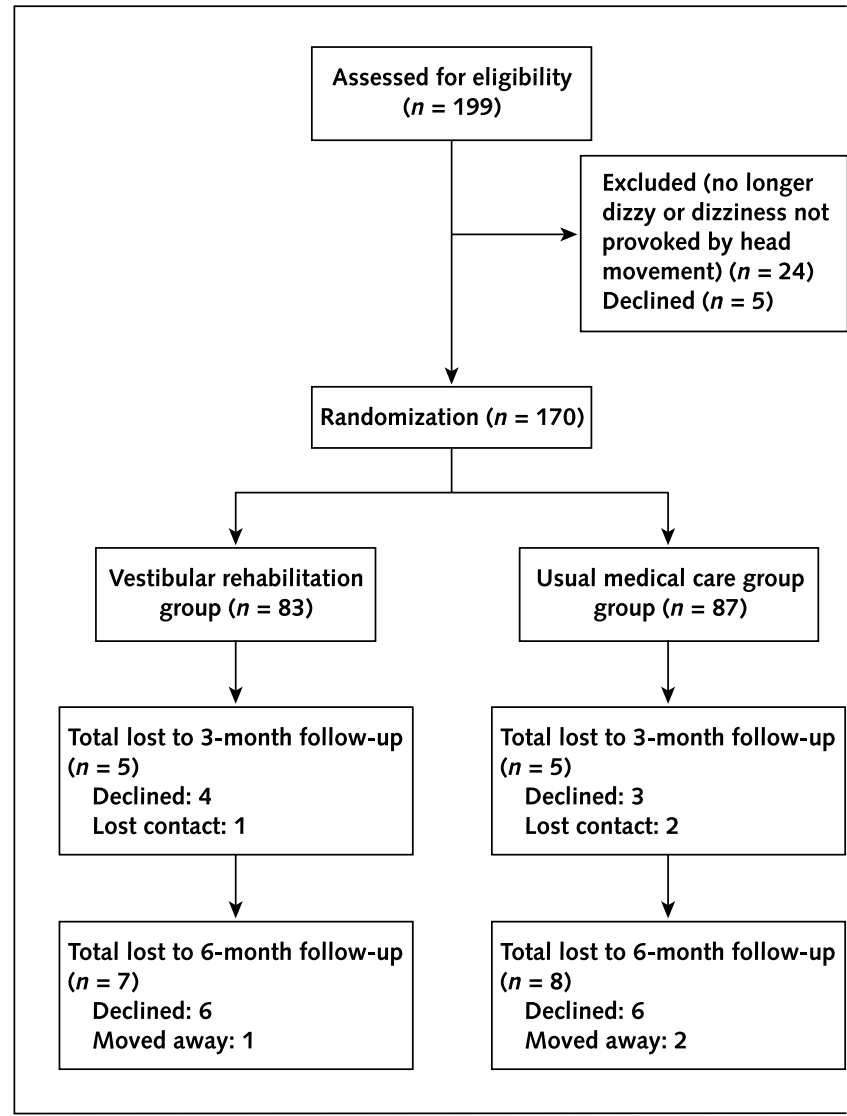

United Kingdom, and included inner-city, suburban, and rural practices. Participating practices had participants with varying levels of social deprivation, as assessed from census data (Jarman scores [30] ranged from -6.49 to 29.11; mean, 8.65). Practice staff used the medical records in the practice to identify all patients with dizziness during the past 2 years. After we screened for exclusion criteria, patients were invited by letter to participate in the study. Practices used the following search terms to identify potentially suitable patients from their computerized databases (terms used varied according to how patient data were recorded by the practice): vertigo, dizziness, Ménière disease, ENT [ear, nose, throat] referral, balance problems, vestibular, prochlorperazine, cinnarizine, betahistine, and diuretics. Patients could also be directly recruited by their general practitioner, and posters displayed in practices informed patients that they could ask to participate. Exclusion criteria were as follows: identifiable nonlabyrinthine cause of dizziness in patient records, duration of dizziness less than 2 months during the past 2 years, medical contraindications for making required head movements (for example, severe cervical disorder), and serious comorbid conditions (for example, life-threatening condition or progressive central disorder). Before randomization, we also excluded patients if they were no longer found to be dizzy at the baseline assessment or if none of the rehabilitation exercises provoked dizziness. In this context, the rehabilitation exercises served as a screening test to identify patients with movement-provoked dizziness, which is typical of vestibular imbalance and should therefore respond to vestibular rehabilitation.

After baseline assessment to confirm eligibility and obtain data for stratification, participants were randomly assigned by an administrative assistant with no previous contact with the patient. Allocation, concealed in opaque sealed envelopes, was based on block randomization within practice (block size, 4) after stratification for severity of

\section{Table 1. Steps of Nurse-Delivered Vestibular Rehabilitation*}

\section{Step Content \\ Nurse explains the rationale for vestibular rehabilitation, eliciting and addressing any doubts and concerns about dizziness and vestibular rehabilitation (for example, How can vestibular rehabilitation reduce my dizziness? Can it cause me any harm?). \\ Nurse describes and takes the patient through the set of standard head and eye exercises (consisting of moving the head as far and fast as comfortably possible, first from side to side and then up and down, with eyes open with and without fixation and with eyes closed) (Appendix 1 video, available at www.annals.org).}

Nurse asks the patient to identify and record in the booklet (Appendix 3A, available at www.annals.org) a suitable home location and 2 times during which the patient can do the exercises every day.

$4 \quad$ Nurse teaches the patient how to monitor recovery by using standardized exercises and dizziness ratings recorded weekly in the booklet; the nurse then teaches the patient to tailor the intensity and difficulty of the exercises he or she carries out to his or her stage of recovery (for example, perform movements slowly while sitting when the level of provoked symptoms is high and then perform them faster, standing, or walking as provoked symptoms lessen).

$5 \quad$ Nurse helps the patient to select daily activities to encourage physical and psychological adaptation in everyday situations (for example, walking, traveling, or participating in sports).

$6 \quad$ Nurse suggests additional customized exercises, as necessary, to treat particular forms of dizziness or imbalance (for example, induced by position or visual motion).

Nurse advises on how to anticipate and cope with obstacles to adherence (for example, transient increases in symptoms due to illness, fatigue, or stress).

$8 \quad$ Patient carries out exercises and activities daily at home, as specified in steps $2,3,5$, and 6 , for a period of 12 weeks (or until exercises provoke no dizziness); the patient monitors and adjusts the program as instructed in step 4.

9 Nurse provides support and advice in 2 follow-up telephone calls, 1 and 3 weeks after the initial session covering steps $1-7$. The follow-up consists of checking and encouraging adherence, asking the patient to report the latest ratings of provoked symptoms, and using this information to recommend tailored changes in the exercise regimen.

Patient continues to carry out exercises and activities daily at home as specified in steps 2, 3, 5, and 6 (monitoring and adjusting the program as instructed in step 4), for 3 months or until dizziness no longer provoked by any movement.

\footnotetext{
* Steps 1-7 are delivered in the initial 30-40 minutes.
} 
symptoms on the Vertigo Symptom Scale-Short Form (28) (Figure 1) (low severity, $<12$ points; high severity, $\geq 12$ points). On the basis of findings from the previous primary care study (28), we estimated that with a sample size of 86 patients per group, we should be able to detect an effect size of 0.5 on the Vertigo Symptom Scale-Short Form with a 2 -tailed significance level of $5 \%$ and $90 \%$ power. After we made the exclusions (Figure 2), 87 patients were randomly assigned to the usual medical care group and 83 were assigned to the treatment group.

\section{Intervention}

The nurses $(n=23)$ attended a single half-day group training session at which they learned how to teach patients to carry out vestibular rehabilitation exercises at home (Table 1 and Appendix 1 video; all appendix material is available at www.annals.org). For a full description of the materials used by nurses, see Appendix 2A (rationale for nurse and patient education), Appendix 2B (workshop structure for nurse training), Appendix $2 \mathrm{C}$ (schedule for vestibular rehabilitation sessions), and the Appendix Figure (patient therapy monitoring sheet). The vestibular rehabilitation program was focused on a professionally designed treatment booklet for patients (Appendix 3A [booklet] and Appendix 3B [supplement to booklet for patients with Ménière disease]) and was developed by using principles of behavior change derived from theory and research on adherence (techniques included eliciting and addressing concerns, providing evidence of efficacy, requiring the patient to make a specific goal plan and written commitment, monitoring and reinforcing progress, and teaching skills to cope with setbacks) $(31,32)$. Patients were actively involved in adapting the exercise program to suit their symptoms, capabilities, and lifestyle. Nurses saw patients individually for 30 to 40 minutes to take them through the booklet and gave additional support and advice by telephone at 1 and 3 weeks after this initial session (Appendix 2C). Participants in both groups remained free to continue their usual medical care, including use of medications and referral to specialties.

\section{Outcome Measures}

The primary outcome measures were self-reported spontaneous and provoked symptoms of dizziness, dizziness-related quality of life, and objective measurement of postural stability with eyes open and eyes closed. Spontaneous symptoms were evaluated with the Vertigo Symptom Scale-Short Form (28), a questionnaire that assesses the frequency of 15 dizziness-related symptoms during the past month on a 5-point scale. Clinically significant change on this questionnaire was defined as a change in score of at least 3 points. We measured quality-of-life effects of dizziness by the Dizziness Handicap Inventory (33), which consisted of 25 items rated on a 3-point scale.

Postural stability was assessed by using the Balance Performance Monitor (SMS Technologies, Harlow, United Kingdom), a portable device that measures movements of the center of pressure induced by the sway of the individual when standing still on a footplate equipped with pressure sensors. The measure used was mean sway path (23) in millimeters (that is, total movement of the center of pressure during a 30-second trial), summed over 2 trials with eyes open and 2 trials with eyes closed. If a participant could not complete the test, his or her data were coded as missing because an accurate sway path could not be assigned.

Provoked symptoms were assessed by asking participants to rate their dizziness on a scale of 0 (no symptoms) to 2 (marked dizziness) after performing a standardized set of head movements. If the movements could be done with-

Table 2. Comparison of Primary and Secondary Outcome Measures at 3-Month Follow-up, Adjusted for Baseline Levels*

\begin{tabular}{|c|c|c|c|c|c|c|}
\hline \multirow[t]{2}{*}{ Measuret } & \multirow{2}{*}{$\begin{array}{l}\text { Patients with } \\
\text { Baseline Data, } \\
n\end{array}$} & \multirow{2}{*}{$\begin{array}{l}\text { Patients with } \\
\text { Missing Data, } \\
n \neq\end{array}$} & \multicolumn{2}{|c|}{ Score for Outcome Measure } & \multirow[t]{2}{*}{ Difference between Groups§ } & \multirow[t]{2}{*}{$P$ Value $\|$} \\
\hline & & & $\begin{array}{l}\text { Vestibular } \\
\text { Rehabilitation } \\
\text { Group }\end{array}$ & $\begin{array}{l}\text { Usual Medical } \\
\text { Care Group }\end{array}$ & & \\
\hline \multicolumn{7}{|l|}{ Primary outcome measures } \\
\hline Vertigo Symptom Scale & 170 & 13 & $9.88 \pm 0.76$ & $13.3 \pm 0.74$ & $-3.48(-5.59$ to -1.38$)$ & 0.001 \\
\hline Movement-provoked dizziness & 169 & 17 & $14.55 \pm 1.19$ & $20.69 \pm 1.14$ & $-6.15(-9.40$ to -2.90$)$ & 0.001 \\
\hline Dizziness Handicap Inventory & 170 & 18 & $31.09 \pm 1.52$ & $35.88 \pm 1.48$ & $-4.78(-8.98$ to -0.59$)$ & 0.026 \\
\hline \multicolumn{7}{|l|}{ Secondary outcome measures } \\
\hline $\begin{array}{l}\text { Short Form-36 (physical } \\
\text { functioning) }\end{array}$ & 169 & 17 & $27.14 \pm 0.47$ & $25.95 \pm 0.45$ & $1.18(-0.09$ to 2.46$)$ & 0.069 \\
\hline HADS (anxiety) & 170 & 18 & $6.22 \pm 0.28$ & $6.92 \pm 0.28$ & $-0.70(-1.48$ to 0.08$)$ & 0.079 \\
\hline HADS (depression) & 170 & 18 & $4.42 \pm 0.07$ & $4.41 \pm 0.07$ & $0.01(-0.19$ to 0.21$)$ & $>0.2$ \\
\hline
\end{tabular}

${ }^{*}$ HADS $=$ Hospital Anxiety and Depression Scale. Values with a plus/minus sign are the mean $( \pm S E)$.

† For all measures except Short Form-36, lower values indicate better functioning (that is, reduction in symptoms or disability).

\# The number of participants with missing data includes those who dropped out of the trial.

$\S$ For all measures except Short Form-36, a reported negative between-group difference indicates greater improvement in the vestibular rehabilitation group. The differences reported here have been rounded.

|| Between-group differences in outcome at 3 months, adjusted for baseline by using analysis of covariance. 
out provoking symptoms while seated, they were repeated while standing. A constant of 3 was added to the score for movements that could not be performed while standing, and a maximum score of 6 was assigned if the movements could not be completed. Scores were summed across 6 sets of movements (head shake and head nod, with eyes open, eyes fixated on a stable point, and eyes closed).

Secondary outcome measures were anxiety and depression, assessed by the Hospital Anxiety and Depression Scale (34), and scores on the physical functioning scale of the Medical Outcomes Study Short Form-36 quality-oflife questionnaire (35). At baseline, we also recorded demographic characteristics (age, sex, most recent occupation, or occupation of spouse if not in paid employment), duration of dizziness, and use of medication for dizziness; after treatment, the questionnaire asked about adherence to therapy. Occupation was categorized by using the National Statistics Socio-economic Classifications. We could not classify the occupations of 10 people.

We mailed the questionnaires for self-completion before the visits of the blinded research assistant. This assistant assessed provoked symptoms and postural stability at baseline and at 3 and 6 months and followed up in person on missing data on the questionnaire. If any participants inadvertently indicated which group they were in, the researcher recorded that the blinding procedure had been unsuccessful in this case.

\section{Statistical Analysis}

The administrative assistant entered the data, which was double-checked by the research assistant. The trial was analyzed on an intention-to-treat basis, using SPSS statistical software, version 11.00 (SPSS Inc., Chicago, Illinois). For participants lost to follow-up (Figure 2) and other missing data (Tables 2 and 3), we brought forward the score from baseline, imputing no change.

We compared the groups at baseline by using chisquare and $t$-tests. We then compared group outcomes at 3 months, after adjustment for the baseline level of the outcome measure, by using analysis of covariance. We calculated within-group changes on outcome measures between the 3-month and 6-month follow-up (with CIs) to evaluate whether treatment effects were maintained in the intervention group 3 months after the end of the intervention and whether treatment effects were observed in the usual medical care group after those participants had also received the intervention.

\section{Role of the Funding Source}

The funding source approved the original design of the study through a process of peer review but had no role in the collection, analysis, or interpretation of the data or in the decision to submit the manuscript for publication.

\section{RESULTS}

Table 4 shows baseline characteristics of participants in the 2 groups. The groups did not differ significantly on any variable at baseline ( $P>0.2$ for all variables). The average duration of dizziness was more than 8 years. Diagnoses recorded by primary care staff were vertigo of unknown cause $(n=40)$, dizziness of unknown cause $(n=$

Table 3. Mean Changes in Outcome Measures between 3-Month and 6-Month Follow-up*

\begin{tabular}{|c|c|c|c|c|c|c|c|c|}
\hline \multirow[t]{3}{*}{ Measuret } & \multicolumn{4}{|c|}{ Vestibular Rehabilitation Group } & \multicolumn{4}{|c|}{ Usual Medical Care Group } \\
\hline & \multicolumn{2}{|c|}{ Patients, $n$} & \multirow{2}{*}{$\begin{array}{l}\text { Mean Change during } \\
\text { Postintervention Period } \\
(95 \% \mathrm{Cl})\end{array}$} & \multirow{2}{*}{$\begin{array}{l}P \\
\text { Value§ }\end{array}$} & \multicolumn{2}{|c|}{ Patients, $n$} & \multirow{2}{*}{$\begin{array}{l}\text { Mean Change before and } \\
\text { after Study }(95 \% \mathrm{Cl})\end{array}$} & \multirow{2}{*}{$\begin{array}{l}P \\
\text { Value§ }\end{array}$} \\
\hline & $\begin{array}{l}\text { With } \\
\text { Baseline } \\
\text { Data }\end{array}$ & $\begin{array}{l}\text { Baseline } \\
\text { Data } \\
\text { Missing‡ }\end{array}$ & & & $\begin{array}{l}\text { With } \\
\text { Baseline } \\
\text { Data }\end{array}$ & $\begin{array}{l}\text { Baseline } \\
\text { Data } \\
\text { Missing‡ }\end{array}$ & & \\
\hline \multicolumn{9}{|l|}{$\begin{array}{c}\text { Primary outcome } \\
\text { measures }\end{array}$} \\
\hline Vertigo Symptom Scale & 83 & 16 & $0.66(-0.61$ to 1.94$)$ & $>0.2$ & 87 & 14 & $-2.49(-4.15$ to 0.83$)$ & 0.004 \\
\hline $\begin{array}{l}\text { Movement-provoked } \\
\text { dizziness }\end{array}$ & 82 & 21 & $0.28(-1.76$ to 2.32$)$ & $>0.2$ & 87 & 16 & $-9.24(-11.94$ to -6.54$)$ & 0.001 \\
\hline $\begin{array}{l}\text { Postural stability, eyes } \\
\text { open }\end{array}$ & 82 & 13 & $39.09(-3.69$ to 81.86$)$ & 0.073 & 86 & 14 & $-28.00(-92.04$ to 36.05$)$ & $>0.2$ \\
\hline $\begin{array}{l}\text { Postural stability, eyes } \\
\text { closed }\end{array}$ & 76 & 13 & $-15.45(-51.96$ to 21.06$)$ & $>0.2$ & 84 & 14 & $-73.19(-125.34$ to -21.04$)$ & 0.007 \\
\hline $\begin{array}{l}\text { Dizziness Handicap } \\
\text { Inventory }\end{array}$ & 83 & 15 & $-0.42(-3.03$ to 2.18$)$ & $>0.2$ & 87 & 14 & $-6.67(-9.74$ to 3.59$)$ & 0.001 \\
\hline \multicolumn{9}{|l|}{$\begin{array}{l}\text { Secondary outcome } \\
\text { measures }\end{array}$} \\
\hline $\begin{array}{l}\text { Short Form-36 (physical } \\
\text { functioning) }\end{array}$ & 83 & 15 & $-1.13(-2.04$ to -0.23$)$ & 0.015 & 87 & 15 & $-1.34(-2.30$ to 0.39$)$ & 0.006 \\
\hline HADS (anxiety) & 83 & 15 & $-0.11(-0.71$ to 0.50$)$ & $>0.2$ & 87 & 14 & $-0.90(-1.44$ to 0.35$)$ & 0.001 \\
\hline HADS (depression) & 83 & 15 & $-0.13(-0.68$ to -0.42$)$ & $>0.2$ & 87 & 14 & $-0.48(-0.99$ to 0.02$)$ & 0.059 \\
\hline
\end{tabular}

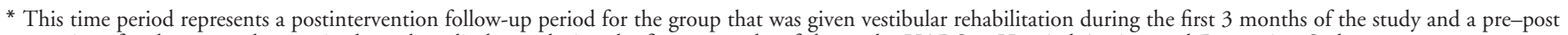
comparison for the group that received usual medical care during the first 3 months of the study. HADS $=$ Hospital Anxiety and Depression Scale.

† For all measures except Short Form-36, negative values indicate improvement in functioning (that is, reduction in symptoms or disability).

¥ The number of participants with missing data includes those who dropped out of the trial.

$\S$ Significance of paired $t$-test. 
Table 4. Baseline Characteristics of Participants Allocated to Vestibular Rehabilitation and Usual Medical Care during the First 3 Months of the Trial*

\begin{tabular}{|c|c|c|}
\hline \multirow[t]{2}{*}{ Characteristic } & \multicolumn{2}{|c|}{ Intervention Group } \\
\hline & $\begin{array}{l}\text { Vestibular } \\
\text { Rehabilitation } \\
(n=83)\end{array}$ & $\begin{array}{l}\text { Usual Medical Care } \\
(n=87)\end{array}$ \\
\hline Age & $62.93 \pm 15.21$ & $61.01 \pm 14.42$ \\
\hline Duration of dizziness, mo & $98.00 \pm 141.48$ & $101.01 \pm 135.25$ \\
\hline Women, $n(\%)$ & $59(71)$ & $62(71)$ \\
\hline \multicolumn{3}{|l|}{ Occupation, $n(\%)$} \\
\hline Managerial or professional & $39(36)$ & $33(22)$ \\
\hline Intermediate & $18(23)$ & $23(28)$ \\
\hline Routine or semiroutine & $21(27)$ & $26(32)$ \\
\hline $\begin{array}{c}\text { Patients taking medication } \\
\text { for dizziness, } n(\%)\end{array}$ & $44(53)$ & $43(49)$ \\
\hline $\begin{array}{l}\text { Patients who had previously } \\
\text { undertaken balance } \\
\text { retraining, } n(\%)\end{array}$ & $3(4)$ & $2(2)$ \\
\hline \multicolumn{3}{|l|}{$\begin{array}{l}\text { Baseline score for outcome } \\
\text { measures }\end{array}$} \\
\hline Vertigo Symptom Scale & $16.57 \pm 11.28$ & $14.70 \pm 9.21$ \\
\hline $\begin{array}{l}\text { Movement-provoked } \\
\text { dizziness }\end{array}$ & $27.28 \pm 5.72$ & $26.56 \pm 7.64$ \\
\hline $\begin{array}{l}\text { Postural stability, eyes } \\
\text { open }\end{array}$ & $586.49 \pm 249.27$ & $561.38 \pm 278.66$ \\
\hline $\begin{array}{l}\text { Postural stability, eyes } \\
\text { closed }\end{array}$ & $897.99 \pm 459.94$ & $820.27 \pm 422.45$ \\
\hline $\begin{array}{l}\text { Dizziness Handicap } \\
\text { Inventory }\end{array}$ & $40.98 \pm 22.52$ & $37.89 \pm 19.74$ \\
\hline $\begin{array}{l}\text { Short Form-36 (physical } \\
\text { functioning) }\end{array}$ & $65.67 \pm 30.30$ & $69.37 \pm 27.28$ \\
\hline HADS (anxiety) & $7.37 \pm 4.60$ & $7.24 \pm 4.66$ \\
\hline HADS (depression) & $3.77 \pm 3.10$ & $3.48 \pm 2.67$ \\
\hline
\end{tabular}

* Values with a plus/minus sign are the means $( \pm S D)$. HADS $=$ Hospital Anxiety and Depression Scale.

$31)$, Ménière disease $(n=16)$, labyrinthitis $(n=15)$, benign positional vertigo $(n=9)$, vestibular imbalance or disorder $(n=4)$, vestibular neuronitis $(n=3)$, and otologic disorder $(n=5)$. No diagnosis was recorded for 47 patients. Nearly half of the participants (83 of 170) reported that they were currently taking antivertiginous or antiemetic medication (chiefly betahistine, prochlorperazine, or cinnarizine), but only 5 of 170 participants (3\%) had previously been offered vestibular rehabilitation.

At the 3-month follow-up, improvement on all primary outcome measures was significantly greater in the vestibular rehabilitation group than in the usual medical care group (Table 2). These findings remained significant when we repeated the analyses while omitting the participants (48 of 170 [28\%]) who had inadvertently given some potential clue to the research assistant about their treatment status. The relative risk for clinically significant improvement in scores on the Vertigo Symptom Scale in the vestibular rehabilitation group compared with the usual medical care group was 1.78 (95\% CI, 1.31 to 2.42 ); 56 of 83 patients $(67 \%)$ in the vestibular rehabilitation group reported improvement compared with 33 of 87 (38\%) in the usual medical care group. At baseline, all participants had provoked symptoms after head movement, but at the 3-month follow-up, 19 of 82 patients (23\%) in the vestibular rehabilitation group had no provoked symptoms at all compared with 5 of 87 patients $(6 \%)$ in the usual medical care group (relative risk, 4.03 [CI, 1.58 to 10.30]).

Six-month follow-up (Table 3) of the group given vestibular rehabilitation during the first 3 months of the study showed that improvement obtained during treatment was maintained during the subsequent 3 months (that is, significant deterioration did not occur on any measure except the Short Form-36). The usual medical care group received vestibular rehabilitation during this period and improved significantly on 6 of the 8 outcome measures. At the 6-month follow-up, the groups did not differ significantly on any measure $(P>0.15)$.

Self-reported adherence was fair, with 120 of 170 participants $(71 \%)$ reporting carrying out the exercises most days of the week; only 93 of $170(55 \%)$ continued with the exercises for at least 9 weeks or until their symptoms ceased. Telephone counseling was given to 146 of 170 patients $(85 \%) 1$ week after their initial therapy session and to 130 of 170 patients $(76 \%) 3$ weeks after the first session. No serious medical problems that may have been related to participants' dizziness were reported by patients or nurses during the trial. Seven participants reported minor, transient side effects: cervical symptoms $(n=4)$, feelings of nausea $(n=1)$, a pricking sensation in the feet $(n=1)$, and pressure in the head $(n=1)$.

\section{Discussion}

Our findings indicate that vestibular rehabilitation introduced and supervised by nurses in primary care can reduce symptoms, disability, and handicap resulting from chronic dizziness, and this improvement is maintained for at least 3 months after treatment. More than two thirds of patients in the intervention group reported a clinically significant improvement in symptoms after treatment compared with just over one third of the usual medical care group. In addition, almost 4 times as many treated patients as controls had no provoked symptoms at all. These results are similar to those achieved in secondary care; compensation is often partial (13), and although some trials of secondary care treatment report slightly better recovery rates, these studies were based on more highly selected samples of patients who were more likely to respond well, did not include dropouts or nonadherent participants in their analyses, or did not use blind evaluation (20-26).

A limitation of this study is that participants could not be blinded to treatment status, and most of the outcome measures were based on subjective reports. Consequently, reported improvement could be due to nonspecific psychological effects of therapy, which are common in dizzy patients. Although psychological improvement is an anticipated and welcome outcome of vestibular rehabilitation (19), the pattern of results is more consistent with a specific treatment effect on vestibular symptoms. Treatment 
effects were strongest for symptoms and handicap directly related to balance system dysfunction (provoked and spontaneous vestibular symptoms and dizziness-related handicap) and were weak or nonsignificant for measures of general physical and psychological well-being (anxiety, depression, and physical functioning). Objective measures of postural stability also confirmed improvement after treatment, and the greater improvement in stability with eyes closed than with eyes open is consistent with a reduction in vestibular imbalance $(21,23,36)$.

An additional limitation is that the participants were a largely self-selected subsample of those with dizziness in primary care. Because the success of vestibular rehabilitation relies on the willingness of patients to practice daily head movements that will initially make their symptoms worse, this treatment could be less effective when prescribed than in our volunteers. For ethical reasons, we were obliged in our recruitment letter to emphasize that initial side effects were to be expected and recovery was likely to be partial. Allowing patients offered this treatment to have an equally realistic appreciation of its benefits and drawbacks may maximize effectiveness by ensuring that only those who are as committed as our participants accept treatment.

Because nurse-delivered vestibular rehabilitation in primary care involves only a single, brief consultation, it would be valuable to determine its cost-effectiveness relative to the current alternatives of medication or specialist treatment. Definitive diagnoses for dizziness are frequently not recorded in primary care, and initial assessments are typically insufficient to exclude serious causes of dizziness. Therefore, an important feature of our design was that all patients remained free to seek concurrent consultations and treatment from other health professionals, including specialists. Although diagnosis was unrelated to treatment outcome in the only previous primary care study of vestibular rehabilitation (28), it would be useful to identify the proportions and disease characteristics of patients who can be safely and effectively managed solely in primary care and those who require specialist care. Relevant characteristics could include cause (for example, some central and recurrent disorders are likely to benefit from specialist assessment and management) and comorbid conditions (for example, patients with a stiff or painful neck that limits their ability to perform the exercises might benefit from physiotherapist involvement).

For the primary care physician, dizziness presents a frustrating condition with few treatment options. In an aging population, this is a growing problem that contributes to the morbidity, mortality, economic costs, and reduced quality of life associated with falling and fear of falling in later life $(5,6,37)$. We believe that our study is the first large-scale trial of vestibular rehabilitation that conforms to CONSORT criteria, tests the effectiveness of vestibular rehabilitation for a heterogeneous primary care sample with dizziness due to various causes, and evaluates whether practice staff with minimal training can appropriately select and treat patients. Our study provides a substantive demonstration that it is feasible to offer an effective, inexpensive treatment to patients with dizziness in primary care. In our sample, the mean duration of participants' dizziness was 8 years, and fewer than $3 \%$ of patients had previously been offered vestibular rehabilitation. A single, brief session with the nurse was sufficient to significantly reduce symptoms, handicap, and postural instability resulting from dizziness. We have demonstrated that nurses in primary care can effectively perform vestibular rehabilitation after a half day of training by using a booklet that supports both nurse and patient in understanding and appropriately tailoring the therapy. Our findings also indicate that, despite the difficulty of diagnosis, general practitioners can identify patients who can safely benefit from rehabilitation in primary care.

From University of Southampton, Southampton; Brighton and Sussex Medical School, Brighton; and Imperial College London, London, United Kingdom.

Note: This trial is registered as ISRCTN63019017 on the metaRegister of Controlled Trials, National Health Service Research and Development Regional Programmes.

Acknowledgments: The authors thank Dr. John Beasley, who ensured that the generalizability of these findings was not lost because of international differences in health care delivery and terminology.

Grant Support: By grant SEO 083 from the Directorate of Health and Social Care South, London, United Kingdom.

Potential Financial Conflicts of Interest: None disclosed.

Requests for Single Reprints: Lucy Yardley, PhD, School of Psychology, University of Southampton, Highfield, Southampton SO17 1BK, United Kingdom; e-mail, L.Yardley@soton.ac.uk.

Current author addresses and author contributions are available at www .annals.org.

\section{References}

1. Kroenke K, Hoffman RM, Einstadter D. How common are various causes of dizziness? A critical review. South Med J. 2000;93:160-7; quiz 168. [PMID: 10701780]

2. Yardley L, Owen N, Nazareth I, Luxon L. Prevalence and presentation of dizziness in a general practice community sample of working age people. Br J Gen Pract. 1998;48:1131-5. [PMID: 9667086]

3. Yardley L, Burgneay J, Andersson G, Owen N, Nazareth I, Luxon L. Feasibility and effectiveness of providing vestibular rehabilitation for dizzy patients in the community. Clin Otolaryngol. 1998;23:442-8. [PMID: 9800081]

4. Sloane P, Blazer D, George LK. Dizziness in a community elderly population. J Am Geriatr Soc. 1989;37:101-8. [PMID: 2783432]

5. Burker EJ, Wong H, Sloane PD, Mattingly D, Preisser J, Mitchell CM. Predictors of fear of falling in dizzy and nondizzy elderly. Psychol Aging. 1995; 10:104-10. [PMID: 7779308]

6. Friedman SM, Munoz B, West SK, Rubin GS, Fried LP. Falls and fear of falling: which comes first? A longitudinal prediction model suggests strategies for primary and secondary prevention. J Am Geriatr Soc. 2002;50:1329-35. [PMID: 


\section{7}

7. Sloane PD, Coeytaux RR, Beck RS, Dallara J. Dizziness: state of the science. Ann Intern Med. 2001;134:823-32. [PMID: 11346317]

8. Bird JC, Beynon GJ, Prevost AT, Baguley DM. An analysis of referral patterns for dizziness in the primary care setting. Br J Gen Pract. 1998;48:1828-32. [PMID: 10198501]

9. Hoffman RM, Einstadter D, Kroenke K. Evaluating dizziness. Am J Med. 1999;107:468-78. [PMID: 10569302]

10. Hanley K, O' Dowd T. Symptoms of vertigo in general practice: a prospective study of diagnosis. Br J Gen Pract. 2002;52:809-12. [PMID: 12392120]

11. Yardley L, Burgneay J, Nazareth I, Luxon L. Neuro-otological and psychiatric abnormalities in a community sample of people with dizziness: a blind, controlled investigation. J Neurol Neurosurg Psychiatry. 1998;65:679-84. [PMID: 9810937]

12. Tinetti ME, Williams CS, Gill TM. Dizziness among older adults: a possible geriatric syndrome. Ann Intern Med. 2000;132:337-44. [PMID: 10691583]

13. Brandt T. Management of vestibular disorders. J Neurol. 2000;247:491-9. [PMID: 10993488]

14. Hanley K, O'Dowd T, Considine N. A systematic review of vertigo in primary care. Br J Gen Pract. 2001;51:666-71. [PMID: 11510399]

15. Colledge NR, Barr-Hamilton RM, Lewis SJ, Sellar RJ, Wilson JA. Evaluation of investigations to diagnose the cause of dizziness in elderly people: a community based controlled study. BMJ. 1996;313:788-92. [PMID: 8842072] 16. Rascol O, Hain TC, Brefel C, Benazet M, Clanet M, Montastruc JL. Antivertigo medications and drug-induced vertigo. A pharmacological review. Drugs. 1995;50:777-91. [PMID: 8586026]

17. Cooksey FS. Rehabilitation in vestibular injuries. Proc R Soc Med. 1945;39: 273-8.

18. Herdman SJ, ed. Vestibular Rehabilitation. Philadelphia: FA Davis; 1999. 19. Beidel DC, Horak FB. Behavior therapy for vestibular rehabilitation. J Anxiety Disord. 2001;15:121-30. [PMID: 11388355]

20. Cohen HS, Kimball KT. Increased independence and decreased vertigo after vestibular rehabilitation. Otolaryngol Head Neck Surg. 2003;128:60-70. [PMID: 12574761]

21. Horak FB, Jones-Rycewicz C, Black FO, Shumway-Cook A. Effects of vestibular rehabilitation on dizziness and imbalance. Otolaryngol Head Neck Surg. 1992;106:175-80. [PMID: 1738550]

22. Johansson M, Akerlund D, Larsen HC, Andersson G. Randomized controlled trial of vestibular rehabilitation combined with cognitive-behavioral therapy for dizziness in older people. Otolaryngol Head Neck Surg. 2001;125:151-6.
[PMID: 11555746]

23. Strupp M, Arbusow V, Maag KP, Gall C, Brandt T. Vestibular exercises improve central vestibulospinal compensation after vestibular neuritis. Neurology. 1998;51:838-44. [PMID: 9748036]

24. Krebs DE, Gill-Body KM, Parker SW, Ramirez JV, Wernick-Robinson M. Vestibular rehabilitation: useful but not universally so. Otolaryngol Head Neck Surg. 2003;128:240-50. [PMID: 12601321]

25. Shepard NT, Telian SA. Programmatic vestibular rehabilitation. Otolaryngol Head Neck Surg. 1995;112:173-82. [PMID: 7816453]

26. Steenerson RL, Cronin GW. Comparison of the canalith repositioning procedure and vestibular habituation training in forty patients with benign paroxysmal positional vertigo. Otolaryngol Head Neck Surg. 1996;114:61-4. [PMID: 8570252]

27. Altman DG, Schulz KF, Moher D, Egger M, Davidoff F, Elbourne D, et al. The revised CONSORT statement for reporting randomized trials: explanation and elaboration. Ann Intern Med. 2001;134:663-94. [PMID: 11304107]

28. Yardley L, Beech S, Zander L, Evans T, Weinman J. A randomized controlled trial of exercise therapy for dizziness and vertigo in primary care. Br J Gen Pract. 1998;48:1136-40. [PMID: 9667087]

29. Pocock SJ. Clinical Trials. Chichester, United Kingdom: Wiley; 1983.

30. Jarman B. Identification of underprivileged areas. Br Med J (Clin Res Ed). 1983;286:1705-9. [PMID: 6405943]

31. Myers LB, Midence K, eds. Adherence to Treatment in Medical Conditions. Amsterdam: Harwood Academic; 1998.

32. Resnick B. A seven step approach to starting an exercise program for older adults. Patient Educ Couns. 2000;39:243-52. [PMID: 11040724]

33. Jacobson GP, Newman CW. The development of the Dizziness Handicap Inventory. Arch Otolaryngol Head Neck Surg. 1990;116:424-7. [PMID: 2317323]

34. Zigmond AS, Snaith RP. The hospital anxiety and depression scale. Acta Psychiatr Scand. 1983;67:361-70. [PMID: 6880820]

35. Ware JE, Kosinski M. SF-36 Physical and Mental Health Summary Scales: A Manual for Users of Version 1. 2nd ed. Lincoln, Rhode Island: QualityMetric Inc; 1994.

36. Ojala M, Matikainen E, Juntunen J. Posturography and the dizzy patient: a neurological study of 133 patients. Acta Neurol Scand. 1989;80:118-22. [PMID: 2816273]

37. Kristinsdottir EK, Jarnlo GB, Magnusson M. Asymmetric vestibular function in the elderly might be a significant contributor to hip fractures. Scand J Rehabil Med. 2000;32:56-60. [PMID: 10853718] 


\section{Patient Therapy Monitoring Sheet}

Patient name Telephone

Diagnosis

Scores: $0=$ no symptoms $1=$ very slight symptoms $2=$ mild symptoms $3=$ strong symptoms

$\mathrm{S}=$ sitting $\mathrm{ST}=$ standing $\mathrm{W}=$ walking

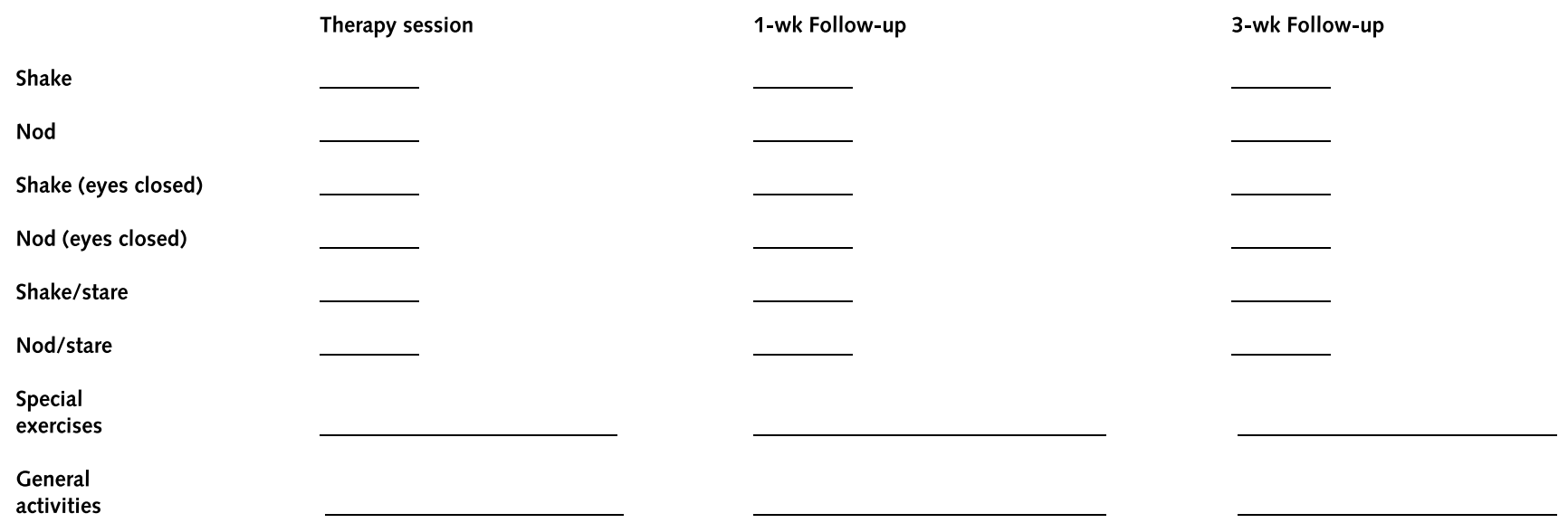

General comments: (including any particular patient concerns, goals, or problems, nonadherence, setbacks)

\section{Appendix 2A: Rationale for Nurse and Patient EDUCATION}

The patient booklet has been designed to:

a) answer frequently asked questions regarding the rationale for therapy and its likely effects;

b) help the patient to tailor the therapy to suit their symptoms, capabilities and lifestyle;

c) help the patient to adhere to therapy by setting definite objectives and monitoring progress.

Although the booklet is largely self-explanatory, patients are likely to need personal reassurance and encouragement in order to feel sufficiently confident and motivated to deliberately carry out activities that provoke dizziness in order to recover. The aim of the training session with the nurses is to:

a) provide them with sufficient knowledge about the therapy to reassure and guide patients;

b) teach some basic psychological techniques for helping patients to adhere to the therapy.

The training session takes one half-day, and alternates going through each section of the patient booklet with oppor- tunities for the nurses to role play a set of typical patient cases (which they find particularly helpful-as trainer I generally left the room during these to reduce embarrassment, but then discussed any queries arising when I returned). It is helpful if the trainer for these sessions has some expertise in vestibular rehabilitation, and its psychological aspects, but a bibliography is given below for those who do not. It is also helpful to provide nurses and patients with evidence of the efficacy of the therapy, to eliminate any scepticism (e.g. descriptions by patients, published trials). There is also a summary sheet to guide nurses through their patient session and remind them what they need to check in terms of patient understanding and concerns; they can practice using this for their role play sessions.

The training session is based on the same psychological techniques as the booklet, i.e. it is important to elicit, acknowledge and address nurses' concerns about whether they can do this effectively, first demonstrate and then allow them to practice the techniques, provide them with a structure for ensuring adherence to the method as demonstrated (e.g. guidelines/checklist for pa-

\footnotetext{
19 October $2004 \mid$ Annals of Internal Medicine $\mid$ Volume 141 • Number 8|W-115
} 
tient sessions), and provide positive social support, with the promise of follow-up advice if needed.

\section{Bibliography}

Pavlou M, Shumway-Cook A, Horak F, Yardley L, Bronstein A. Rehabilitation of balance disorders in the patient with vestibular pathology. In: Bronstein A, Brandt T, Woolacott M, Nutt JG, eds. Clinical Disorders of Balance and Gait Disorders. London: Edward Arnold; 2004:317-43.

Yardley L, Jahanshahi M, Hallam R. Psychosocial aspects of disorders affecting balance and gait. In: Bronstein A, Brandt T, Woolacott M, Nutt JG, eds. Clinical Disorders of Balance and Gait Disorders. London: Edward Arnold; 2004:360-84.

Herdman SJ, ed. Vestibular Rehabilitation. Philadelphia: FA Davis; 1999.

Yardley L. Overview of psychologic effects of chronic dizziness and balance disorders. Otolaryngol Clin North Am. 2000; 33:603-16. [PMID: 10815039]

\section{Useful Internet Sources}

www.vestibular.org/compensation.html

www.menieres.co.uk/vertigo_and_dizziness.html (can download L. Yardley "Vertigo and Dizziness" from this site; this is a book describing the experience and causes of dizziness in terms many patients and beginning therapists find useful, with clear explanations for the many different symptoms and provocative factors).

\section{ApPendix 2B: Workshop Structure for NURSE TRAINING}

9:15-9:30 Introduce training team. Explanation of structure of workshop.

9:30-9:50 Explanation of balance system and rationale for therapy (i.e. pages 1-3 of booklet). From this part of the training nurses should learn how movement initially provokes dizziness but then produces compensation. They should be able to reassure patients that it is suitable for many causes of dizziness and has been proven effective, but they should also learn what (rare) danger signs to alert patients to.

9:50-10:30 Exercise 1. Fostering appropriate attitudes and expectations.

Form trainees into groups of three. Each group member in turn should take 10 minutes to act as:

a) therapist, explaining balance system and rationale for therapy, and checking for understanding/agreement

b) patient (with concerns the therapist must uncover)

c) observer, timing explanation, and checking:

- explanation of key points

- use of clear and simple language

- provision of good examples

- elicitation of patient perspective

- addressing patient concerns

Constructive feedback should then be provided briefly to "therapist" by observer and "patient."

10:30-10:50 Explanation of how to carry out basic exercises, demonstrating each and asking trainees to do each one (check they do them correctly, at right speed and with sufficient head movement). Explanation of how patient should select exercises, record them in booklet, and update selection each week.

10:50-11:10 TEA BREAK (20 minutes) and general discussion

11:10-11:30 Explanation of special exercises and "general activities." Include rationale for these: a) need to practice specific situations and activities provoking dizziness (e.g. positional or visual vertigo) and b) need to become accustomed to dizziness in real-life situations.

11:30-11:45 Discussion of psychological aspects of therapy and encouraging adherence.

Explain importance of eliciting, acknowledging and addressing patient's concerns (first part of booklet). Then explain need to teach patient techniques for encouraging adherence, including: making explicit commitment (when will do exercises, which ones); setting gradual, achievable goals and monitoring progress; selecting activities that will suit them; anticipating/overcoming setbacks (especially increases in dizziness, problems with stiff neck-just do exercises more gently until eases but must still do regularly), including seeking support from family and therapist.

11:45-12:15 Exercise 2. Encouraging adherence.

In groups of three, trainees should take turns as above. The role of the "therapist" this time is to undertake the relapse prevention part of the therapy session.

12:15-12:30 General discussion and questions.

\section{Patient A, Exercise 1}

You are a 60 year old woman who has had head movement provoked dizziness for ten years. The dizziness is mildly unpleasant-bad enough to stop you making quick movements-and you have given up the active pastimes you previously enjoyed with your partner (vigorous walking and dancing). You do not work and no essential activities are prevented by the dizziness. You have simply accepted the dizziness as just an inevitable part of the slowing down process of getting older. Therefore, you are not sure that it is worth the time and discomfort of doing the exercises, or whether they will work at your age and after being dizzy for so long.

[Particular problems: Therapist needs to elicit and address doubts as to whether treatment is effective at her age (therapist can then reassure her that average age in successful clinical trial is over 60), and whether worth doing the exercises (therapist should stress loss of fitness and risk of falling a serious problem as get older, set as goals resuming enjoyed activities with partner-enlist partner's support).]

\section{Patient B, Exercise 1}

You are a 40 year old woman who has been dizzy for two years. You are extremely afraid of the dizzy attacks, which can be brought on or made worse by bending or raising your head. Your father died recently of a stroke, and he used to become dizzy when he tipped his head back, so you think your dizziness may be a sign of being about to have a stroke. Therefore, you think the exercises are not appropriate for your problem, and could be dangerous, and you are frightened of the sensations they provoke.

[Particular problems: Therapist needs to elicit and address con- 
cerns about cause of dizziness—note bending head not sign of dizziness related to stroke, go over contraindications in booklet so patient knows warning signs to look for and is $O K$ if these do not occur, stress that movements are within normal range so should be safe but can see doctor again if still worried. Elicit fear of movement and encourage to begin exercises very gently, only increase rangelspeed of movement if provoked dizziness tolerable when doing it and afterwards.]

\section{Patient C, Exercise 1}

You are an 80 year old man who has had intermittent attacks of severe vertigo for the past year-cause unknown but Ménière's disease not ruled out. In between attacks you have become very unsteady on your feet, especially when turning or bending down. You are extremely frustrated as you were previously very active, and have had to give up riding your bicycle, helping with the Boy's Brigade, and playing in the church brass band. This has led you to become somewhat depressed, and angry with the doctors you have seen, who have been unable to cure the dizziness and have suggested that you need to accept that you should slow down. You are hoping that by carrying out these exercises very vigorously you will be able to completely get rid of all your symptoms in a few weeks, and can then resume the activities you have given up.

[Particular problems: Therapist needs to ensure that expectations are positive but realistic and not over-optimistic (which may lead to disappointment and anger). Elicit information about intermittent attacks and warn that these may periodically cause vestibular imbalance again (see supplement to booklet for people with Ménière's disease) but should help improve symptoms between attacks. Ensure exercises not performed too vigorously at first, as over-performance leads to excessive dizziness which interferes with regular exercising (a disastrous stop-go pattern that often results in frustration and giving up).]

\section{Patient A, Exercise 2}

You are a 45 year old man with his own business, suffering from occasional attacks of dizziness for the past year, with mildly unpleasant dizziness in between, especially when working on the computer for long periods. You travel a great deal (driving), and think it will be hard to find a time and place to carry out the exercises regularly, especially as they are not a high priority for you (since the dizziness is fairly mild and you are not entirely convinced that it is due to balance system dysfunction rather than fatigue and stress).

[Particular problems: Therapist needs to elicit belief that dizziness due to fatiguelstress and test belief by evaluating if movementprovoked-if so, then can demonstrate to patient more likely to be vestibular imbalance. May have visual vertigo provoked by working on computer - recommend tailored exercises for this. Make sure agree time that will be convenient and not interfere with ability to drivemaybe just once a day in the evening. Explain how fatigue/stress may aggravate vestibular symptoms (see Vertigo and Dizziness book) and warn to expect better and worse days, and to do exercises more gently (but not abandon them) on bad days.]

\section{Patient B, Exercise 2}

You are a woman of 73 living alone, in good health apart from the dizziness caused by labyrinthitis six months ago. You are anxious and depressed, having lost your husband recently, and the dizziness makes you more so, especially as you are afraid of falling over and hurting yourself while dizzy at home alone. You are worried about the exercises making the dizziness worse, and not being able to do them safely.

[Particular problems: Therapist needs to elicit fears and reassure exercises can be paced so will help her to be independent and confident rather than add to her problems. Agree very gentle schedule, remind will support her, explore whether other sources of support.]

\section{Patient C, Exercise 2}

You are a woman of 50 who has had fluctuating dizziness for two years since an episode of "flu." The dizziness makes it difficult to work as a teacher sometimes, as it interferes with your concentration, and gets worse when you have to bend over the children. You are worried about suddenly getting very dizzy when driving to work or when caring for young children. You are delighted and reassured that someone has finally been able to explain to you why bending makes it worse and suggest a remedy, and are fully intending to follow the therapy programme to the letter.

[Particular problems: Therapist needs to explain why dizziness may cause concentration problems (see Vertigo and Dizziness book) and explain provoking factors so aware when attacks likely. Make sure agree time that will be convenient and not interfere with ability to drive and care for children - maybe just once a day in the evening. Risk of over-enthusiastic compliance and unrealistic expectations leading to a cycle of alternately provoking severe symptoms by overexercising and not performing the exercises because of dizziness, so warn that most important to take exercises slowly but steadily, warn to expect better and worse days, and to do exercises more gently (but not abandon them) on bad days.]

\section{Appendix 2C. Schedule for Vestibular Rehabilitation Sessions}

Arrange mutually convenient appointment (at practice or home) allowing minimum 45 minutes, and strongly encouraging attendance of family member or friend who can provide support.

\section{Session Structure \\ Understanding and Attitudes (10-15 minutes)}

Ask patient briefly about their problem.

Go through booklet pages 1 to 3 with patient, then check the following points.

Does patient:

- understand how their dizziness may relate to balance system functioning?

- believe that exercises can improve their balance functioning?

- believe that exercise therapy is necessary/beneficial for them?

- believe that therapy will not harm them, and understand contraindications?

- have realistic expectations for short- and longer-term consequences of exercises?

19 October 2004 Annals of Internal Medicine $\mid$ Volume $141 \cdot$ Number $8 \mid$ W-117 


\section{Implementation (15-25 minutes)}

Go through rest of booklet with patient, helping them to complete all sections of chart at back and copying down the current set of exercises selected from the patient booklet to the patient monitoring sheet. Then check following points.

Does patient:

- have commitment to specific place and time which suits them for carrying out exercises?

- understand how to choose appropriate exercises for them?

- understand how to carry out the exercises safely and appropriately (include pacing)?

- agree on exercises to be practised (including special exercises and general activities)?

- feel they have adequate access to social/professional support?

- understand the purpose and timing of monitoring and follow-up of their progress?

\section{Relapse Prevention (5-10 minutes)}

Discuss with patient what problems they anticipate. Do not dismiss these, but discuss ways to minimize costs of therapy, and encourage patient to weigh up relative costs and benefits.

Note that symptoms may temporarily increase with overvigorous exercising, physical or emotional stress, fatigue, illness. Re-emphasize strategy to cope with this of: a) decreasing exercise intensity but NOT regularity, b) seeking social support and professional advice.

Then check the following points:

- Does patient: know that setbacks may occur, especially those specific to their circumstances?

- Know what to do if these setbacks occur, to prevent serious disruption of therapy?

Agree provisional date and time for first follow-up

Follow-up phone calls

Follow-up phone-calls should take place one week and three weeks after therapy session, and last ca. 10 minutes.

\section{Structure of Follow-up}

1. Check adherence first (i.e. discourage focus on symptoms, since too soon to expect to see improvement, may have worsened-should try to ignore at this stage).

2. Congratulate on any adherence (i.e. praise adherence rather than criticize non-adherence).

3. Discuss any barriers to adherence and solutions to these (see previous sections):

- encourage patient to identify problems and help find solutions

- get patient to make new specific commitment to new solutions (what/when/where)

- congratulate patient on creating and committing to these solutions.

4. Check and record patient monitoring and updating of exercise programme, including special exercises and general activities.

5. At first follow-up, remind patient of next follow-up, agree provisional date/time.

\section{Appendix 3B: Balance Retraining: Exercises Which SPEed ReCoVery from DizZiness and UNSTEADINESS}

\section{Supplement for People with Ménière's Disease}

Can balance retraining exercises help someone with Ménière's disease?

"Balance retraining" is a therapy which can speed recovery from any change in balance system function-including changes caused by Ménière's disease. But if you have Ménière's disease, you need to understand the difference between attacks of vertigo (which the exercises cannot help) and long-lasting dizziness and imbalance (which the exercises can help).

Attack of vertigo. This is a strong sensation of spinning which happens suddenly, lasts several hours, and usually causes you to be sick, and to be unable to stand up, walk or drive. In Ménière's disease, attacks of vertigo are caused by changes in the inner ear. The exercises cannot prevent these attacks-but they cannot cause them either. If you are currently having these kinds of attacks very frequently (every six weeks, or more often) then the exercises cannot help you just now, as recovery takes at least six weeks even with the exercises.

Long-lasting dizziness and imbalance. The changes in the inner ear which cause an attack of vertigo result in a change in the signals given out by the faulty balance organ. Over time, your brain adjusts to these new signals (the booklet explains how this happens), and so you become less dizzy. Balance retraining exercises can speed this process of recovery.

Attacks of vertigo do not normally occur very often-usually there are many months or even years between attacks, although there are sometimes periods when the attacks occur frequently. But you may find that in between the attacks of vertigo you have long-lasting symptoms, such as dizziness, nausea, unsteadiness, tiredness, or a "hangover" feeling. These symptoms often become worse when you are physically active, tired, stressed, or when you travel. The exercises can help you to clear up these symptoms during the period in between attacks of vertigo.

Of course, after you have cleared up the long-lasting symptoms, you may have another attack of vertigo. In this case, you will have to start all over again, using the exercises to speed recovery. But people with Ménière's disease who have tried these exercises say that they give them confidence that they will be able to get over their next attack of vertigo more quickly, using the exercises to help to clear up symptoms.

Current Author Addresses: Dr. Yardley and Ms. Donovan-Hall: School of Psychology, University of Southampton, Highfield, Southampton SO17 1BJ, United Kingdom.

Dr. Smith: Division of Primary Care and Public Health, Brighton and Sussex Medical School, University of Brighton, Falmer, Brighton BN1 9PH, United Kingdom.

Dr. Walsh: School of Nursing and Midwifery, University of Southampton, Highfield, Southampton, SO17 1BJ, United Kingdom.

Mr. Mullee: Medical Statistics, Health Care Research Unit and Southampton Statistical Sciences Research Institute, University of Southampton, Highfield, Southampton SO17 1BJ, United Kingdom.

Dr. Bronstein: Division of Neuroscience and Psychological Medicine, 
Imperial College, Charing Cross Hospital, Fulham Palace Road, London W6 8RF, United Kingdom.

Author Contributions: Conception and design: L. Yardley, M. Donovan-Hall, H.E. Smith, B.M. Walsh.

Analysis and interpretation of data: L. Yardley, M. Donovan-Hall, H.E. Smith, M. Mullee, A.M. Bronstein.

Drafting of the article: L. Yardley, B.M. Walsh, M. Mullee, A.M. Bronstein.

Critical revision of the article for important intellectual content: L. Yardley, M. Donovan-Hall, H.E. Smith, B.M. Walsh, A.M. Bronstein.
Final approval of the article: L. Yardley, M. Donovan-Hall, H.E. Smith, B.M. Walsh, M. Mullee.

Provision of study materials or patients: L. Yardley, H.E. Smith. Statistical expertise: L. Yardley, M. Mullee.

Obtaining of funding: L. Yardley, H.E. Smith, B.M. Walsh.

Administrative, technical or logistic support: L. Yardley, M. DonovanHall.

Collection and assembly of data: L. Yardley, M. Donovan-Hall. 